SECCIÓN: Teorías geográficas, geografía de la

cultura y la vida cotidiana
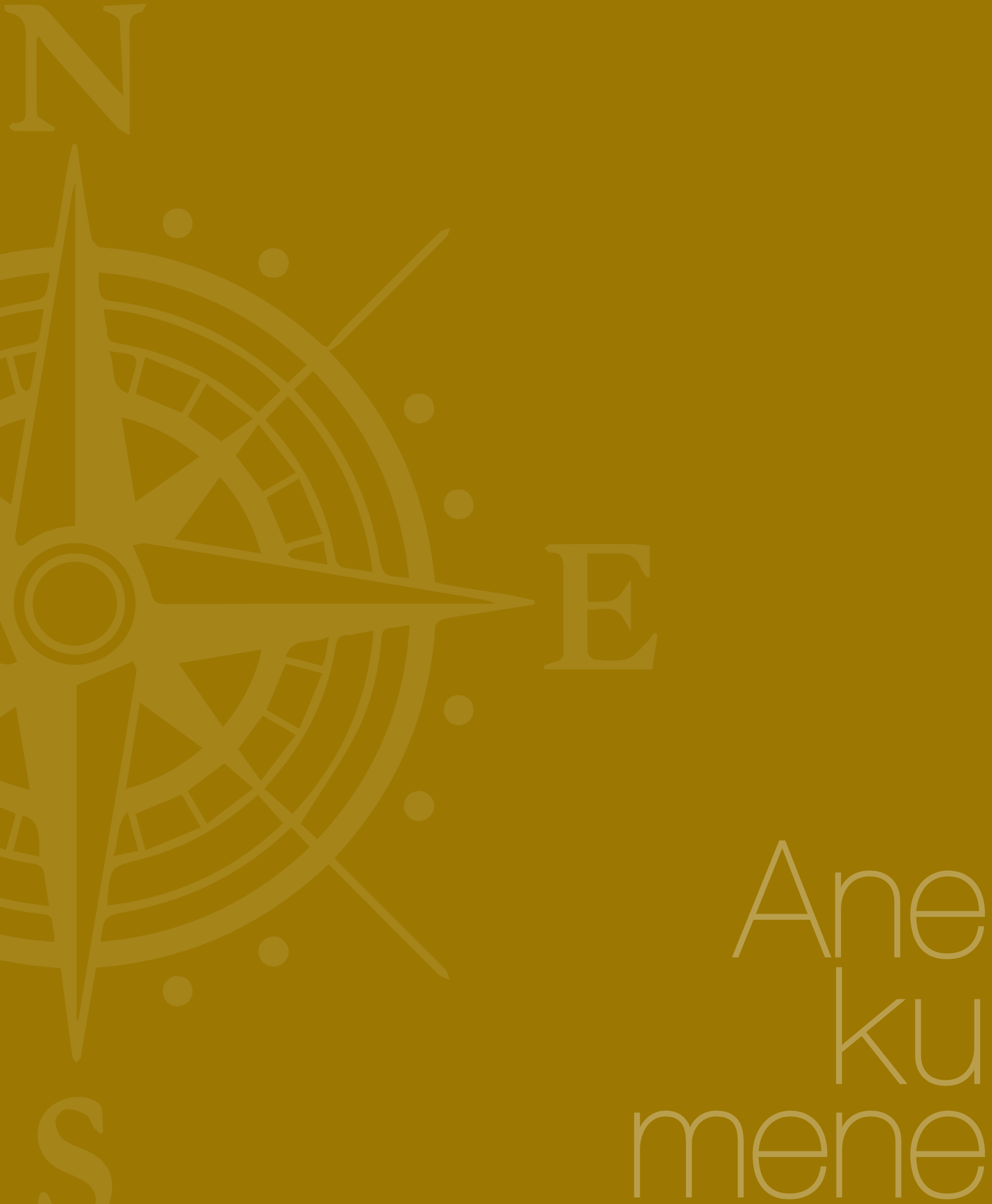


\section{Cartografia escolar e inclusiva para alunos surdos: uma proposta metodológica em movimento}

Cartografía escolar e inclusiva para alumnos sordos: una propuesta metodológica en movimiento

\section{School and Inclusive Cartography for Deaf Students: A Methodological Proposal in Motion}

Pedro Moreira dos Santos Neto*

Miriam Aparecida Bueno**

\begin{abstract}
Resumo
Este artigo refere-se a uma pesquisa de doutorado em andamento que busca apresentar uma proposta metodológica de cartografia escolar e inclusiva para alunos surdos. A pesquisa de campo centrou-se na observação de aulas de Geografia, que possuíam alunos surdos, além da realização de entrevistas, oficina e minicurso. Como resultado preliminar, identificou-se que os alunos surdos têm dificuldades na leitura dos mapas convencionais; todavia, com a produção de mapas em Libras e VisoGrafia (uma modalidade de escrita de sinais), houve melhora no processo de leitura cartográfica.
\end{abstract}

\section{Palavras-chave}

Cartografia escolar, ensino de geografia, educação inclusiva.

\footnotetext{
* Universidade Federal de Goiás.

** Universidade Federal de Goiás
} 


\section{Resumen}

Este artículo se deriva de una investigación de doctorado en curso que busca presentar una propuesta metodológica de cartografía escolar e inclusiva para alumnos sordos. La investigación de campo se centró en la observación de clases de Geografía en grupos con alumnos sordos, además de la realización de entrevistas, talleres y un minicurso. Como resultado preliminar, se identificó que los alumnos sordos tienen dificultades en la lectura de los mapas convencionales; sin embargo, con la producción de mapas en Libras y VisoGrafia (una modalidad de escritura de señales), hubo mejoría en el proceso de lectura cartográfica.

\footnotetext{
Abstract

This article is a product of an ongoing doctoral research that seeks to present a methodological approach to school and inclusive cartography for deaf students. The field research focused on the observation of geography classes, which had deaf students, as well as in some interviews, workshops, and a mini-course. As a preliminary result, the author identified that deaf students have difficulties in reading conventional maps; however, with the production of maps in Libras and VisoGrafia-a type of sign writing-, there was improvement in the cartographic reading process.
}

\section{Palabras clave}

Cartografía escolar, enseñanza de la geografía, educación inclusiva.

\section{Keywords}

School cartography, teaching of geography, inclusive education. 


\section{Introdução}

O presente artigo é fruto da pesquisa de tese que versa sobre o processo de ensino-aprendizagem de Geografia e os níveis de apropriação e produção do mapa pelo aluno surdo, valorizando sua leitura geográfica a partir da potencialidade da linguagem cartográfica. Para tanto, parte-se da realidade concreta dos alunos surdos vislumbrando a produção de mapas que atendam as especificidades linguísticas desses estudantes e que valorizem sua percepção e leitura visual espacial.

Nesta perspectiva, segundo Deliberato (2000), os surdos têm um aumento de amplitude do componente visual oriundo das regiões temporal e frontal do cérebro, refletindo a influência dominante de aderências visuais em células multimodais. Enquanto que o aumento de respostas das regiões occipitais ${ }^{1}$ nos surdos acontece pelo uso da linguagem visual.

A referida autora explica que o surdo depende somente do campo visual para monitorar novas informações, diferente do ouvinte que além do campo visual utiliza o sentido auditivo. Este contexto permite concluir que os surdos possuem visão periférica mais desenvolvida e se diferenciam do ouvinte na percepção visual, principalmente porque "os surdos apresentam aumento de respostas das regiões occipitais em função de um aumento compensatório do sistema visual, em decorrência da privação auditiva" (p. 24).

Deste modo, propõe-se a hipótese de pensar um novo mapa para o aluno surdo que atenda suas especificidades linguísticas e que valorize sua percepção e leitura visual espacial. A proposta de tese neste estudo refere-se a valorização da percepção visual espacial do aluno surdo na perspectiva do espaço vivido, percebido e concebido, contribuindo para o pensamento espacial e a produção cartográfica que atenda as especificidades linguísticas deste aluno, uma vez que a Libras possui uma gramática própria e difere radicalmente da língua oral e escrita. Tendo por base esses parâmetros, este mapa poderá possuir características distintas dos mapas convencionais, ou seja, o mapa terá como base a língua do sujeito em questão, possibilitando que o processo de ensino-aprendizagem de Geografia e a construção do raciocínio geográfico sejam mais efetivos para estes estudantes.

No Brasil existem duas línguas oficiais: a Língua Portuguesa (LP) de uso corrente para os ouvintes e a Língua Brasileira de Sinais (Libras) para os surdos. Mas isso não significa que a LP deve restringir-se somente aos ouvintes e, da mesma forma, a Libras não deve ficar restrita aos surdos. Neste sentido a Libras é considerada uma das línguas oficiais no Brasil

1 Responsável pelo processamento dos estímulos visuais, localiza-se na parte inferior do cérebro. desde a promulgação da lei $n^{\circ} 10.436$, de 24 de abril de 2002, tornando-se a língua oficial de aproximadamente 10 milhões de surdos de acordo com o Instituto Brasileiro de Geografia e Estatística.

Os surdos recebem informações em uma lógica completamente distinta da sua própria condição, fato este que dificulta e especifica o seu ensino na educação básica, uma vez que a comunicação e a linguagem são premissas para o processo de construção do conhecimento individual e coletivo. Diante do exposto cabe alguns questionamentos: a) como que o professor de Geografia que não tem conhecimento em Libras, portanto, não sabe se comunicar com o aluno surdo, vai construir os conteúdos geográficos a partir do cotidiano deste aluno?; b) como os mapas que não estão na língua do aluno surdo são trabalhados em sala de aula?; e c) de que forma a Geografia possibilita desenvolver o raciocínio geográfico a partir da Cartografia Escolar e Inclusiva para alunos surdos?

O decreto n. 5.626, de 26 de dezembro de 2005 prevê o uso de recursos didáticos e avaliações específicas que atendam as necessidades dos alunos surdos, pois as escolas ainda são pensadas para os alunos ditos "normais". A proposta supracitada se justifica uma vez que pretende-se propor neste estudo uma elaboração de Cartografia Escolar e Inclusiva para alunos surdos, no qual os produtos cartográficos buscarão atender as especificidades desses sujeitos.

Assim, o objetivo desse artigo é apresentar os resultados preliminares da tese em construção, que foram obtidos por meio de observações, entrevistas semidirigidas, oficina e minicurso com alunos surdos regularmente matriculados em duas escolas, sendo uma especial e outra inclusiva.

\section{Ensino de Geografia e Cartografia Escolar e Inclusiva}

De acordo com Streiechen (2013), o aspecto visual é a principal mediação no processo comunicativo do aluno surdo. Desse modo, a proposta de Cartografia Escolar e Inclusiva para alunos surdos está fundamentada na potencialidade da percepção visual e leitura espacial do aluno surdo e, também, no uso da Libras e suas possibilidades de escrita na VisoGrafia.

Esse estudo situa-se metodologicamente na pesquisa qualitativa e participante, uma vez que partiu-se da realidade concreta dos alunos surdos para construção da tese. Para tanto, foram escolhidas duas escolas da rede pública de ensino do estado de Mato Grosso (MT), sendo as escolas André Avelino Ribeiro (EEAAR) e Centro Estadual de Atendimento e Apoio ao Deficiente Auditivo (CEAADA), ambas localizadas na cidade de Cuiabá/MT. A primeira escola é inclusiva com turmas do Ensino Médio, tendo alunos ouvintes e surdos matriculados, enquanto que a segunda escola é especial, atendendo somente alunos surdos no Ensino Fundamental I E II. 
A escolha de uma escola inclusiva e outra especial ocorreu em razão de que foram observadas aulas em turmas que só têm alunos surdos e em turmas que têm alunos surdos e ouvintes, com o intuito de compreender como o professor de Geografia desenvolve o trabalho escolar em situações diversas. A partir desses contextos vivenciados nas observações e nas entrevistas semidirigidas 2 foi possível desenvolver algumas análises prévias sobre o processo de ensino-aprendizagem de Geografia, identificando as condições que estes alunos surdos estão inseridos no espaço escolar, os níveis de apropriação do conhecimento, a produção do mapa que considere a Libras como idioma de referência e a percepção e a leitura visual e espacial dos alunos surdos.

A tese encontra-se estruturada em três eixos centrais, sendo o primeiro chamado de Ensino-Aprendizagem em Geografia, o segundo de Direitos Civis e Sociais do Surdo na Educaçao e, por fim, o terceiro eixo intitulado de Cartografia Escolar e Inclusiva. É válido mencionar que os eixos apresentados estão permanentemente articulados entre si, pois durante a fase da pesquisa teórico-metodológica estes eixos centrais estarão em constante diálogo.

No eixo Ensino-Aprendizagem de Geografia estão sendo analisados os Projetos Políticos Pedagógicos (PPP) das escolas supracitadas, assim como também as aulas de Geografia, vislumbrando compreender como os professores ensinam os conteúdos geográficos na perspectiva visual e espacial da Cartografia. Busca-se nesse primeiro momento reconhecer e identificar como os parâmetros linguísticos da Libras e da escrita de sinais devem ser considerados nos mapas, valorizando a linguagem visual e espacial do aluno surdo no ensino de Geografia.

O eixo Direitos Civis e Sociais do Surdo na Educação é responsável por analisar os instrumentos jurídicos que regulamentam a Libras, o profissional tradutor intérprete da Libras, a educação especial no tocante da inclusão dos alunos surdos e o currículo de Geografia na Educação Básica. Concomitantemente, encontra-se em processo de análise os Parâmetros Curriculares Nacionais (PCN) de Geografia, as Orientações Curriculares do Estado de Mato Grosso, a Lei de Diretrizes e Bases da Educação Nacional (LDB) e a Base Nacional Comum Curricular (BNCC), com intuito de investigar como se realiza a inclusão dos alunos surdos tanto no aspecto legal quanto no aspecto social do ensino. Além disso, esta parte objetiva compreender as implicações destes instrumentos jurídicos no ensino-aprendizagem de Geografia e na inclusão escolar.

Já o eixo Cartografia Escolar e Inclusiva busca apresentar alguns elementos fundamentais para se trabalhar mapas com os alunos surdos. No primeiro momento foi desenvolvido uma oficina com intuito de mapear as transformações espaciais advindas das obras da Copa do Mundo de 2014 realizadas na cidade de Cuiabá/MT. Deste modo, ao serem mapeadas

\footnotetext{
2 Entrevistas semidirigidas com alunos surdos, professores de Geografia, tradutores
} e intérpretes da Libras e coordenação pedagógica das escolas em questão. as transformações espaciais oriundas das obras de mobilidade urbana com os alunos surdos buscou-se desenvolver o pensamento espacial e as implicações disto na vida dos próprios alunos.

Neste contexto foi trabalhado e desenvolvido a percepção visual espacial do aluno surdo na linguagem cartográfica para representação do espaço geográfico, buscando nesse momento identificar quais elementos eram necessários constar no mapa com os alunos surdos. Também foi realizado um minicurso objetivando o estudo dos elementos cartográficos (título, orientação, coordenadas, legenda, escala gráfica e numérica) e a produção de mapas do perímetro urbano, divisão dos bairros, quadras, ruas e casas dos alunos surdos, requerendo a análise multiescalar, observação, descrição, reflexão e representação, e tendo as categorias lugar e paisagem para compreensão dos processos da produção do espaço geográfico.

A oficina e minicurso foram desenvolvidos com os alunos surdos e com a presença dos professores de Geografia na finalidade de analisar os níveis de apropriação e produção cartográfica do aluno surdo na perspectiva do espaço vivido, percebido e concebido. Estes elementos tiveram por objetivo valorizar o aspecto visual espacial da Libras e também da Geografia no sentido da construção do conhecimento mediado pelo professor e na relação dialética entre o cotidiano do aluno surdo e a ciência geográfica.

A partir das leituras de Sacks (1998), Skliar (1999), Deliberato (2000), Perlin (2001), Guarinello (2007), Cormedi (2010), Quadros e Karnopp (2004), Stumpf (2005), Strobel (2008), Almeida (2012), Streiechen (2013) e Honora (2014), buscou-se compreender as especificidades dos alunos surdos e quais são suas diferenças em relação aos alunos ouvintes e os desdobramentos histórico, social, biológico, linguístico e cultural oriundo da privação da audição e pelo uso do sistema complexo da Libras.

Para o ensino de Geografia e a construção do raciocínio geográfico a reflexão se apropriou dos fenômenos geográficos produzidos pelos alunos surdos na cidade de Cuiabá/MT, partindo dos espaços de vivência e na relação destes com as categorias de lugar e paisagem para compreensão dos processos da produção do espaço geográfico. Nessa perspectiva, os embasamentos teóricos partiram dos seguintes autores: Santos (1985, 1994, 1996), Carlos (2007), Lefebvre (2008), Callai (2009), Pontuschka, Paganelli e Cacete (2009), Cavalcanti (2011, 2012), Corrêa (2012) e Harvey (2012).

No que tange à linguagem cartográfica, parte-se da concepção de que a Cartografia tem papel crucial no processo de ensino-aprendizagem dos alunos surdos, sendo um importante recurso pedagógico para construção do raciocínio geográfico, pois o mapa compreendido como linguagem, representação e comunicação permite que o sujeito compreenda a relação entre os conteúdos e fenômenos geográficos com suas espacialidades. Nessa abordagem, foram utilizados os seguintes autores: Harley (1991), Vasconcellos (1993), Passini, Almeida e Martinelli (1999), Girardi (2003), Simielli (1999; 2014), Richter (2010), Almeida e Passini (2011), Passini (2012), Almeida (2007), Oliveira (2007), Martinelli (2007; 2014). 


\section{O mapa para alunos surdos: uma proposta preliminar}

Durante as etapas do trabalho de campo (Quadro 1) foi possível identificar as dificuldades das escolas especial e inclusiva a partir do relato dos profissionais da educação que atuam nestas instituições e dos alunos surdos no processo de ensino-aprendizagem. Essas dificuldades estão relacionadas ao fato de que existem desencontros linguísticos entre os sujeitos ouvintes e surdos e, também, a ausência de materiais didáticos específicos para se trabalhar pedagogicamente com os alunos surdos.

Quadro 1. Pesquisa de campo

\begin{tabular}{|c|c|c|c|c|}
\hline Turmas & Escola & $\begin{array}{l}\text { Instrumento de } \\
\text { Coletas de } \\
\text { dados I } \\
\text { Observações }\end{array}$ & $\begin{array}{l}\text { Instrumento de } \\
\text { Coletas de dados II } \\
\text { Entrevistas }\end{array}$ & $\begin{array}{l}\text { Instrumento de } \\
\text { Coletas de } \\
\text { dados III } \\
\text { Oficina/ } \\
\text { Minicurso }\end{array}$ \\
\hline $\begin{array}{l}6^{\circ} \text { ano } \\
\text { E.F. II }\end{array}$ & $\begin{array}{l}\text { CEAADA } \\
\text { Especial }\end{array}$ & $\begin{array}{l}\text { Abril e Maio de } \\
\qquad 2017 \\
10 \text { Aulas de } \\
\text { Geografia }\end{array}$ & $\begin{array}{l}\text { Junho e Julho de } 2017 \\
3 \text { Alunos surdos } \\
1 \text { Prof. de Geografia } \\
1 \text { Coord. Pedagógica }\end{array}$ & - \\
\hline $\begin{array}{l}8^{\circ} \text { ano } \\
\text { E.F. II }\end{array}$ & $\begin{array}{l}\text { CEAADA } \\
\text { Especial }\end{array}$ & $\begin{array}{l}\text { Abril e Maio de } \\
\qquad 2017 \\
10 \text { Aulas de } \\
\text { Geografia }\end{array}$ & $\begin{array}{c}\text { Junho e Julho de } 2017 \\
3 \text { Alunos surdos } \\
1 \text { Prof. de Geografia } \\
1 \text { Coord. Pedagógica }\end{array}$ & $\begin{array}{c}\text { Agosto de } 2017 \\
8 \text { Alunos surdos } \\
1 \text { Prof. de } \\
\text { Geografia }\end{array}$ \\
\hline $\begin{array}{c}1^{\circ} \text { ano } \\
\text { E.M. }\end{array}$ & $\begin{array}{l}\text { EEAAR } \\
\text { Regular }\end{array}$ & $\begin{array}{l}\text { Abril e Maio de } \\
\qquad 2017 \\
10 \text { Aulas de } \\
\text { Geografia }\end{array}$ & $\begin{array}{c}\text { Junho e Julho de } 2017 \\
1 \text { Aluno surdo } \\
1 \text { Prof. de Geografia } \\
1 \text { Intérprete de Libras } \\
1 \text { Coord. Pedagógica }\end{array}$ & - \\
\hline $\begin{array}{c}2^{\mathrm{a}} \text { ano } \\
\text { E.M. }\end{array}$ & $\begin{array}{l}\text { EEAAR } \\
\text { Regular }\end{array}$ & $\begin{array}{l}\text { Abril e Maio de } \\
\qquad 2017 \\
10 \text { Aulas de } \\
\text { Geografia }\end{array}$ & $\begin{array}{l}\text { Junho e Julho de } 2017 \\
1 \text { Aluno surdo } \\
1 \text { Prof. De Geografia } \\
1 \text { Intérprete de Libras } \\
1 \text { Coord. Pedagógica }\end{array}$ & - \\
\hline
\end{tabular}

Fonte: Santos (2018).
Durante as observações de 40 aulas de Geografia, 18 entrevistas semidirigidas, 1 oficina e 1 minicurso com 8 alunos surdos e um professor de Geografia, foi possível identificar que os alunos surdos não têm dificuldades na leitura de imagens de satélites, conseguindo diferenciar os alvos imageados, por exemplo. Entretanto, em referência a leitura do mapa convencional os alunos surdos encontraram dificuldades na medida em que os elementos cartográficos são construídos em uma língua distinta da sua e, mais do que isso, uma língua que necessita da audição e oralidade para seu efetivo aprendizado.

A partir deste contexto cabe destacar que o mapa não poderia ser diferente da língua em que este sujeito se comunica com o mundo, uma vez que o mapa além de ser uma representação bidimensional de uma determinada superfície terrestre também é uma linguagem e uma forma de comunicação. Por este motivo não buscou-se apenas identificar quais e como os elementos cartográficos podem constar nos mapas, mas como também elaborar uma proposta de produção cartográfica que atenda os alunos surdos e que possibilite a leitura do mapa em sua totalidade (Quadro 2).

Quadro 2. Elementos cartográficos em Cartografia Escolar e Inclusiva para alunos surdos.

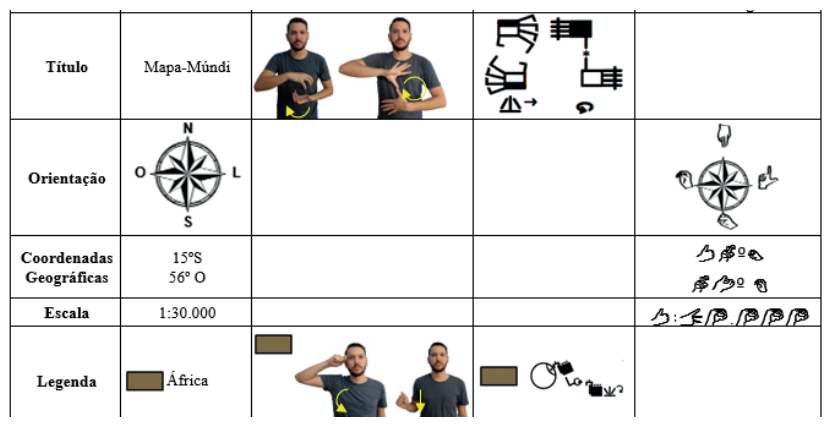

Fonte: Quadro produzido pelo autor a partir do instrumento de coleta de dados I, II E III.

Todo mapa tem minimamente alguns elementos que auxiliam para sua leitura espacial e localização geográfica. Se o mapa é para o aluno surdo, logo, este mapa tem que ser pensado na lógica e no contexto do aluno surdo. Isto significa que o mapa deve ser estruturado de acordo com as condições deste sujeito, considerando sua cultura, sua identidade, sua língua e sua leitura espacial. Ou seja, considerar o sujeito na relação com sua língua e apropriação espacial.

Diante dos resultados preliminares do trabalho de campo foi possível constatar que a produção dos mapas para alunos surdos deveria considerar os parâmetros linguísticos da Libras, uma vez que os mapas convencionais estão em uma língua distinta da língua do aluno surdo. Em outras palavras, se reconhece que falta a língua do aluno surdo no mapa, que faltam os sinais nos lugares das palavras. 
Com base nessas demandas o quadro 2 apresenta algumas possibilidades para esta proposta, como por exemplo o título e a legenda do mapa para os alunos surdos que poderiam ser representados em Libras ou VisoGrafia. Já a orientação, coordenadas geográficas e escalas podem ser representados pela Datilologia, uma vez que estes números não são fixos para toda área de estudo.

A partir desse artigo espera-se contribuir com o processo de ensino-aprendizagem de Geografia e a construção do raciocínio geográfico do aluno surdo, tendo por referência uma proposta de elaboração metodológica de Cartografia Escolar e Inclusiva para alunos surdos.

\section{Considerações finais}

Partimos da perspectiva que o mapa desempenha funções comunicativas e representativas sistematizadas em uma língua e, por isso, são indispensáveis para o trabalho da Geografia na escola. Todavia, os mapas convencionais apresentam um sistema linguístico distinto do usado pelos alunos surdos.

Levando em consideração a potencialidade visual do aluno surdo e também do mapa em espacializar os fenômenos geográficos é que se propõe um mapa que atenda às necessidades linguísticas dos alunos surdos, em razão de que o mapa convencional não possibilita que o aluno surdo realize na sua totalidade a leitura e, consequentemente, a análise dos fenômenos geográficos na relação com a espacialidade. Logo, o mapa convencional apresenta pouco sentido para o aluno surdo, fato este que dificulta ao estudante em compreender a Geografia a partir de sua complexidade e totalidade, ou seja, de construir um raciocínio geográfico.

Assim, torna-se essencial pensar as relações entre a ciência geográfica, o mapa e a língua do sujeito que realizará a leitura e análise do produto cartográfico. A partir desse movimento é que o mapa específico para alunos surdos possibilitará a construção e aprendizagem do conhecimento geográfico e permitirá que este sujeito esteja mais incluído na escola.

\section{Referências}

Almeida, E. (2012). Leitura e Surdez: um estudo com adultos não oralizados. Rio de Janeiro: Revinter.

Almeida, R. (2007). Uma proposta metodológica para a compreensão de mapas geográficos. In R. Almeida (Ed.), Cartografia Escolar (pp. 119-144). São Paulo: Contexto.

Almeida, R. e Passini, E. (2011). O espaço geográfico: ensino e representação. São Paulo: Contexto.
Callai, H. (2009). O Lugar e o Ensino Aprendizagem da Geografia. In M. Pereira (Ed.), La Espesura del Lugar: reflexiones sobre el espacio em el mundo educativo (pp. 171-190). Santiago: Universidad Academia de Humanismo Cristiano.

Carlos, A. (2007). O lugar no/do Mundo. São Paulo: Labur.

Cavalcanti, L. (2011). Ensinar Geografia para autonomia do pensamento. Revista da Anpege, 7(1), 193-203.

Cavalcanti, L. (2012). O Ensino de Geografia na Escola. Campinas: Papirus.

Cormedi, M. (Ed.). (2010). Estudos sobre a Deficiência Auditiva e Surdez. Brasília

Corrêa, R. (2012). Espaço: um conceito-chave da Geografia. In I. Castro, P. Gomes, R. Corrêa (Eds.), Geografia: conceitos e temas (pp. 15-47). Rio de Janeiro: Bertrand Brasil.

Decreto $N^{\circ}$. 5.626. Presidência da República Federativa do Brasil, Brasília, Brasil, 22 de dezembro de 2005.

Deliberato, D. (2000). Aspectos da percepção visual em pré-escolares surdos e ouvintes (tese de doutorado). Universidade Estadual de Campinas, São Paulo, Brasil.

Girardi, G. (2003). Cartografia Geográfica: considerações críticas e proposta para ressignificação de práticas cartográficas na formação do profissional em Geografia (tese de doutorado). Universidade de São Paulo, São Paulo, Brasil.

Guarinello, A. (2007). O papel do outro na escrita de sujeitos Surdos. São Paulo: Pleus.

Harley, J. (1991). A nova história da cartografia. O Correio da Unesco, 19(8), 4-9.

Harvey, D. (2012). O espaço como palavra-chave. GEographia, 14(28), $8-39$

Honora, M. (2014). Inclusão educacional de alunos com surdez: concepção e alfabetização. São Paulo: Cortez.

Lefebvre, H. (2008). Espaço e política. Belo Horizonte: EdufmG.

Lei № ${ }^{\circ}$ 10.436. Presidência da República Federativa do Brasil, Brasília, Brasil, 24 de abril de 2002.

Martinelli, M. (2007). A sistematização da Cartografia temática. In R. Almeida (Ed.), Cartografia Escolar. São Paulo: Contexto.

Martinelli, M. (2014). Mapas, gráficos e redes: elabore você mesmo. São Paulo: Oficina de Textos. 
Oliveira, L. (2007). Estudo metodológico e cognitivo do mapa. In R. Almeida (Ed.), Cartografia Escolar (pp. 9-41). São Paulo: Contexto.

Passini, E, Almeida, R. e Martinelli, M. (1999). A Cartografia Para Crianças: alfabetização, educação ou iniciação cartográfica. Boletim de Geografia, 17, 125-136.

Passini, E. (2012). Alfabetização cartográfica e a aprendizagem de Geografia. São Paulo: Cortez.

Perlin, G. (2001). Identidades surdas. In C. Skliar (Ed.), A surdez: um olhar sobre as diferenças. Porto Alegre: Mediação.

Pontuschka, N., Paganelli, T. e Cacete, N. (2009). Para Ensinar e Aprender Geografia. São Paulo: Cortez.

Quadros, R. e Karnopp, L. (2004). Língua de sinais brasileira: estudos linguísticos. Porto Alegre: Artemed.

Richter, D. (2010). Raciocínio geográfico e mapas mentais: a leitura espacial do cotidiano por alunos do Ensino Médio (tese de doutorado). Universidades Estadual Paulista, São Paulo, Brasil.

Sacks, O. (1998). Vendo vozes: uma viagem ao mundo dos surdos. São Paulo: Cia das Letras.

Santos, M. (1985). Espaço e método. São Paulo: Nobel.
Santos, M. (1994). Metamorfoses do espaço habitado. São Paulo: Hucitec.

Santos, M. (1996). Natureza do espaço. São Paulo: Nobel.

Simielli, M. (1999). Cartografia no ensino fundamental e médio. In A. Carlos (Ed.), A Geografia na sala de aula (pp. 92-108). São Paulo: Contexto.

Simielli, M. (2014). O mapa como meio de comunicação e a alfabetização cartográfica. In R. Almeida (Ed.), Cartografia Escolar. São Paulo: Contexto.

Skliar, C. (1999). Atualidade da Educação bilíngüe para surdos: processos e projetos pedagógicos. Porto Alegre: Mediação.

Streiechen, E. (2013). Libras: aprender está em suas mãos. Curitiba: CRV.

Strobel, K. (2008). As Imagens do outro sobre a Cultura Surda. Florianópolis: Ed. da UFSC.

Stumpf, M. (2005). Aprendizagem de Escrita de Língua de Sinais pelo sistema SignWrinting: Línguas de Sinais no papel e no computador. Porto Alegre: UFRGS.

Vasconcellos, R. (1993). A Cartografia Tátil e Deficiente Visual: uma avaliação das etapas de produção e uso do mapa (tese de doutorado). Universidades de São Paulo, São Paulo, Brasil. 